\title{
Pulmonary Deposition Sites of an Inhaled Radiolabeled Submicronic Aerosol
}

\author{
JOHN KAY, GEOFFREY COATES, AND HUGH O'BRODOVICH \\ Departments of Paedatrics and Radiology, McMaster University Health Sciences Centre, Chedoke-McMaster \\ Hospitals, Hamilton, Ontario, Canada L8N $3 Z 5$
}

\begin{abstract}
The clearance rate of aerosolized and deposited ${ }^{99}$ mechnetium diethylenetriamine pentacetate provides an index of lung epithelial permeability. However, the location of the epithelium being assessed is uncertain. We determined the percentage of submicronic aerosol deposited on ciliated and nonciliated airways in healthy and

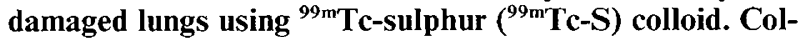
loidal particles can be cleared by mucociliary transport but not through the epithelium. Piglets aged 12-72 h, weighing $0.7-3.3 \mathrm{~kg}$ (average $1.6 \mathrm{~kg}$ ) were anesthetized and underwent endotracheal intubation. ${ }^{99 \mathrm{~m}} \mathrm{Tc}-\mathrm{S}$ labeled submicronic aerosol (Syntevent II) was collected in anesthetic bags and either inhaled spontaneously $(n=4)$, or insufflated by hand $(n=5)$ at 30 breaths per min and a peak airway pressure of $15 \mathrm{~cm} \mathrm{H}_{2} \mathrm{O}$. Piglets were immediately extubated and scanned on a $\gamma$ camera. Twenty-four $h$ later a repeat scan was performed. The residual radioactivity represents the amount of aerosol deposited on nonciliated airways. In six other piglets pulmonary damage was produced by an intravenous infusion of air microemboli for 2 to $3 \mathrm{~h}(0.14$ to $0.38 \mathrm{ml} / \mathrm{min})$. The maximal decrease in $\mathrm{PaO}_{2}$ while breathing room air ranged from $24-59 \mathrm{~mm}$ Hg. During the last 15 min of infusion they were intubated, insufflated by hand with the ${ }^{99 \mathrm{~m}} \mathrm{Tc}-\mathrm{S}$ aerosol, and scanned as above. The results demonstrate that approximately three-fourths of the submicronic aerosol is deposited distally to ciliated airways in both healthy and damaged newborn piglet lungs. This suggests that the clearance rate of ${ }^{99 \mathrm{~m}}$ technetium diethylenetriamine pentacetate predominantly reflects epithelial permeability of terminal lung units when a submicronic aerosol is used for delivery to the lung. (Pediatr Res 20:1297-1300, 1986)
\end{abstract}

Abbreviations
${ }^{99 \mathrm{~m}}$ Tc-DTPA; ${ }^{99 \mathrm{~m}}$ technetium diethylenetriamine pentace-
tate
${ }^{99} \mathrm{mc-S} ;{ }^{99 \mathrm{~m}}$ technetium sulfur colloid
IPPV, intermittant positive pressure ventilation

Acute lung injury syndromes are complicated by pulmonary edema. One potential mechanism for pulmonary edema is increased pulmonary permeability to solutes. The assessment of pulmonary permeability in human infants, however, has been

Received April 24, 1986: accepted July 24, 1986.

Address reprint requests and any correspondence to Hugh O'Brodovich, M.D., Associate Professor of Pediatrics, Pediatric Pulmonary Division, The Hospital for Sick Children, 555 University Avenue. Toronto, Ontario, Canada M5G 1X8.

This work was supported by a grant in aid from the Medical Research Council of Canada MA. 7486. H. O. is a Scholar of the Canadian Heart Foundation and J. K. was supported by John D. Schultz Science Student Scholarship from the Heart and Stroke Foundation of Ontario. difficult due to technical and ethical limitations. Recently our laboratory has been utilizing the pulmonary clearance rate of inhaled and deposited radiolabeled submicronic aerosol as an index of pulmonary epithelial permeability in small lungs (1). It was subsequently observed that premature infants with hyaline membrane disease have increased pulmonary epithelial permeability to the small solute ${ }^{99 \mathrm{~m}} \mathrm{Tc}$-DTPA, and that the permeability returned to normal as the infant improved (2). The location of the epithelium whose permeability was being assessed was uncertain although theoretical calculations suggest that a submicronic radiolabeled aerosol should be deposited predominantly in peripheral lung units (3). Therefore, the objective of the following study was to determine the site of intrapulmonary deposition of a submicronic aerosol in healthy and diseased newborn lungs.

\section{METHODS}

Animal Preparation. Twenty-one newborn piglets (age 12-72 h) who weighed 0.7 to $3.3 \mathrm{~kg}$ (average $1.6 \mathrm{~kg}$ ) were utilized in these experiments. They were sedated and anesthetized by an intramuscular injection of ketamine $(20 \mathrm{mg} / \mathrm{kg})$ and acepromazine $(5$ to $10 \mathrm{mg}$ ). Supplemental doses were administered as required. Body temperature was maintained with overhead heating lamps. Following completion of the initial portion of the protocol (see below) animals were allowed to recover from anesthesia and were nutritionally supported for $24 \mathrm{~h}$ with a synthetic formula suitable for newborn piglets. Following the final measurement, piglets were killed with an intravenous injection of pentobarbital. The chest was rapidly opened, hila cross-clamped, and lungs removed for the determination of the lung wet weight/ dry weight ratio.

Normal lungs. Ten piglets were orally intubated with a 3.0 or $3.5 \mathrm{~mm}$ ID endotracheal tube immediately following induction of anesthesia. They continued to spontaneously inhale room air. The radiolabled submicronic aerosol that had been collected in an anesthetic bag was then either spontaneously inhaled $(n=5)$ or was insufflated by hand at a rate of 30 breaths per minute by a metrinome and a peak airway pressure of $15 \mathrm{~cm} \mathrm{H}_{2} \mathrm{O}(n=5)$. Piglets were then extubated and deposition site of the submicronic aerosol was determined as described below.

Damaged lungs. Eleven piglets had carotid arterial and jugular venous catheters inserted following induction of anesthesia. Pulmonary vascular damage (4) was then induced by intravenously infusing air microemboli at a rate ranging from 0.14 to $0.38 \mathrm{ml} /$ $\min$ for 2 to $3 \mathrm{~h}$. Arterial blood gas tensions and acid base status were measured twice before, and hourly during the infusion of air microemboli. Piglets spontaneously breathed room air throughout the experimental protocol. Five of the piglets did not survive the anesthesia and air infusion and were excluded from any analysis. The remaining six piglets were reintubated $15 \mathrm{~min}$ before discontinuation of the intravenous infusion of microemboli. The submicronic radiolabeled aerosol was then insufflated 
by hand at a rate of 30 breaths per min and a peak inspiratory pressure of $15 \mathrm{~cm} \mathrm{H}_{2} \mathrm{O}$ while maintaining the air infusion. Piglets were then extubated and the deposition of the submicronic aerosol was determined as described below.

Aerosol generation and determination of site of deposition. The underlying principle of the method is that ${ }^{99 \mathrm{~m}} \mathrm{Tc}-\mathrm{S}$ is colloidal and therefore cannot traverse the epithelial membrane. It can, however, be cleared up the mucociliary elevator if it is deposited upon ciliated epithelium. Therefore the amount of ${ }^{99 \mathrm{~m}} \mathrm{Tc}-\mathrm{S}$ remaining in the lung $24 \mathrm{~h}$ after inhalation represents aerosol deposited on nonciliated epithelium.

The radiolabeled submicronic aerosol was prepared by passing oxygen at $10 \mathrm{liter} / \mathrm{min}$ through a jet nebulizer (Syntevent II, Syntex Inc., Palo Alto, CA, now Ultravent, Mallinckodt Inc., St. Louis, MO) containing $3 \mathrm{ml}$ of ${ }^{99 \mathrm{~m}} \mathrm{Tc}-\mathrm{S}$ colloid (average $15 \mathrm{mCi}$ / $\mathrm{ml}$ ). The sulfur colloid is 0.1 to $0.8 \mu$ in diameter. This nebulizer generated an aerosol with an aerodynamic mass median diameter of $0.8 \mu$ and a geometric standard deviation of 1.85 . The radiolabeled aerosol was collected in anesthetic bags and inhaled or insufflated into the piglets' lungs as described above. This size of aerosol is distributed within the lungs in a similar fashion as a gas and is used clinically in the performance of ventilation scintigrams $(5,6)$. The piglets were extubated immediately after insufflation. They were then placed prone and scanned for 100 $s$ on a large field of view $\gamma$ scintillation camera interfaced to a DEC-PDP 11-45 computer. Twenty-four $h$ later the piglets were reanesthetized and scanned for $600 \mathrm{~s}$. In all groups a rectangular area of interest was constructed over the computer image of the scintigram to enclose the lungs from apex to base. Both the entire thorax and only the caudal half of the thorax were separately analyzed and count rates obtained (Fig. 1). The initial scintigram enables definition of the lungs as this aerosol technique is used in ventilation lung scanning $(5,6)$. The division of rostral and caudal half was made by dividing the total number of pixels in half. This image is then stored on computer and used as a template when placing the regions of interest for the 24-h scan. This minimizes the subjectivity of placing regions of interest in the delayed scan. This analysis of the caudal half of the lungs was utilized to evaluate the effect of excluding the counts from the trachea. Room background counts were subtracted from all data and a correction factor for day to day variation in $\gamma$ camera sensitivity was determined by counting a standard of ${ }^{99} \mathrm{~m} \mathrm{Tc}-\mathrm{S}$ after both the initial and 24-h lung scintigrams. Data from the 24-h scintigram was corrected for the physical decay of ${ }^{99 m} \mathrm{Tc}$ (half life $=6.02 \mathrm{~h}$ ). The percentage of colloid remaining in the lungs after $24 \mathrm{~h}$ was taken to be percentage of aerosol deposited on nonciliated epithelium.

Results are reported as mean + SD of the mean. The amount of aerosol deposited on nonciliated airways in the caudal half of the lung was compared between the three groups of animals using unpaired $t$ tests. In view of the multiple comparisons the Bonferroni adjustment was used and only a $p$ value less 0.016 $(0.05 / 3)$ was considered significant.

\section{RESULTS}

The scintigrams from one of the piglets are illustrated in Figure 1. It illustrates the regions of interest used and the 24-h scintigram reveals some radioactivity in the abdomen which represents the deposited ${ }^{99 \mathrm{~m}} \mathrm{Tc}-\mathrm{S}$ that has been transported up the mucociliary elevator and subsequently swallowed. Although this does not ensure normal mucociliary transport it does demonstrate that it
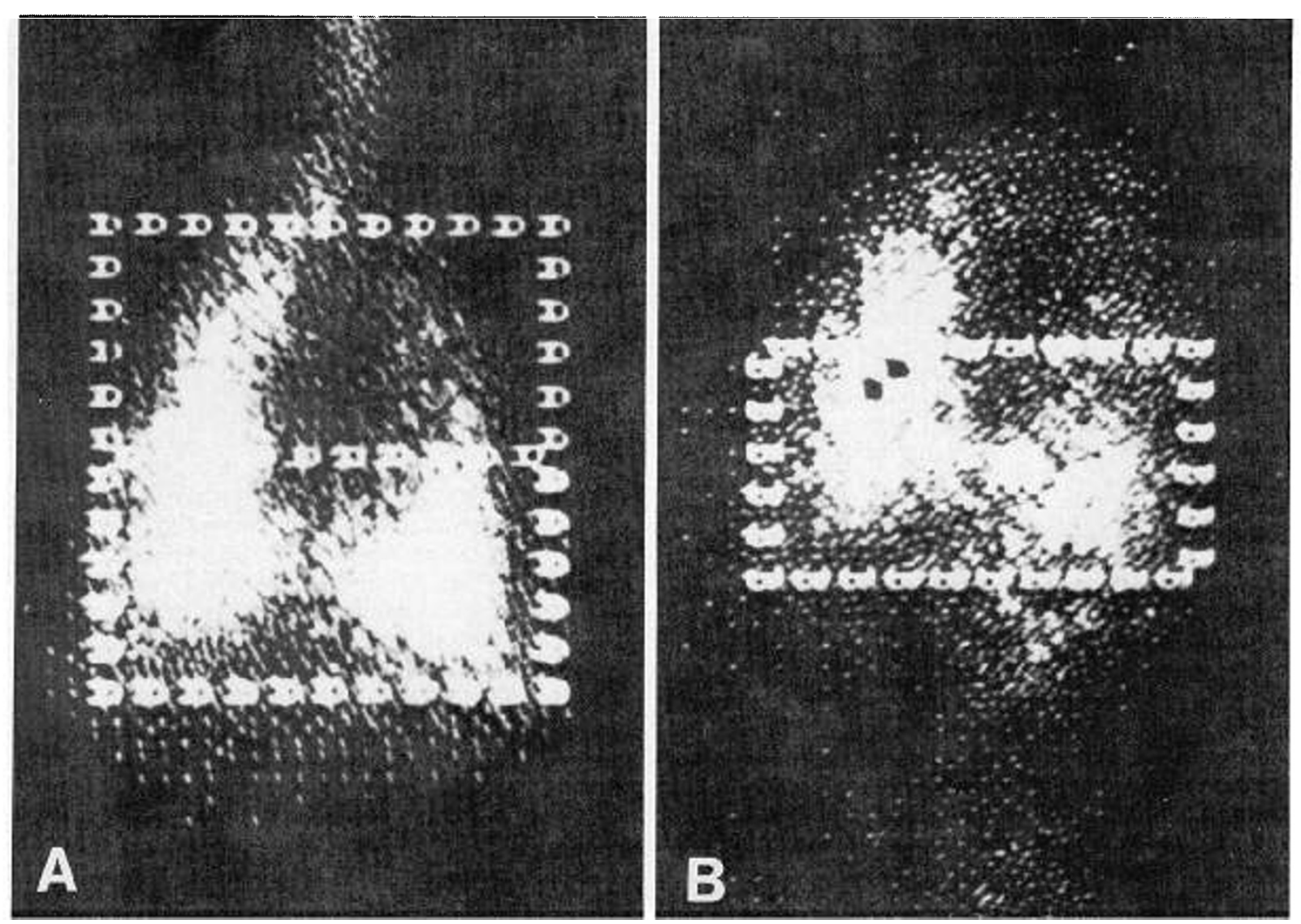

Fig. 1. Lung scintigrams obtained in a healthy newborn piglet immediately $(A)$ and $24 \mathrm{~h}(B)$ after inhaling a ${ }^{99 \mathrm{~m}} \mathrm{Tc}-\mathrm{S}$ labeled submicronic aerosol. In the initial lung scintigram the regions of interest incorporate the entire lungs and are subdivided into equal rostral and caudal halves. In the 24-h scintigram the region of interest is overlying only the caudal half of the lung. Radioactivity can be seen within the abdomen on the 24-h scintigram. This represents ${ }^{99 m} \mathrm{Tc}-\mathrm{S}$ cleared by mucociliary transport and subsequently swallowed. 
was present and not inhibited by the brief period of anesthesia. The entire thorax was used since the shape of the thorax and position of the heart (Fig. 2) resulted in our inability to consistently place a satisfactory separate region of interest around each lung (data not shown).

All piglets with normal lungs survived and were healthy during the 24-h experiment. The amount of aerosol deposited on nonciliated airways in one of the 10 piglets with normal lungs was only half that seen in the other nine piglets. It is unknown why this occurred but because of the marked discrepancy in this one piglet it was excluded from further analysis. The average total counts achieved on the initial scintigram of the whole lung was 46,237 in $100 \mathrm{~s}$ and was 13,529 in $600 \mathrm{~s} 24 \mathrm{~h}$ later. The average total counts achieved on the initial scintigram of the caudal half of the lung was 26;387 in $100 \mathrm{~s}$ and 8,565 in $600 \mathrm{~s} 24 \mathrm{~h}$ later. Background counts averaged $72 \mathrm{cpm}$ and never exceeded 251 $\mathrm{cpm}$. Gamma scintillation camera sensitivity usually varied less than $5 \%$ with the largest difference being $13 \%$ between the initial and delayed scan.

The six piglets who completed air infusion and survived the following $24 \mathrm{~h}$ had a preembolization $\mathrm{PaO}_{2}=102+8 \mathrm{SD} \mathrm{mm}$ $\mathrm{Hg}$. During the embolization, while breathing room air, the $\mathrm{PaO}_{2}$ decreased in each animal (range of maximal decrease was 24 to $59 \mathrm{~mm} \mathrm{Hg}$ ). One hundred percent oxygen was inhaled by one of these piglets during the last $10 \mathrm{~min}$ of the air infusion and the resultant arterial $\mathrm{PO}_{2}$ was $210 \mathrm{~mm} \mathrm{Hg}$. The lung wet to dry weight ratio in the piglets $24 \mathrm{~h}$ after air embolization $(5.3+0.48$, $\mathrm{SD}, n=6)$ was not different from control piglet lungs $(5.8+$ $0.21 \mathrm{SD}, n=4)$.

On average more than $70 \%$ of the submicronic aerosol was deposited on nonciliated airways in all three experimental groups. This result was seen when either the whole lung or the

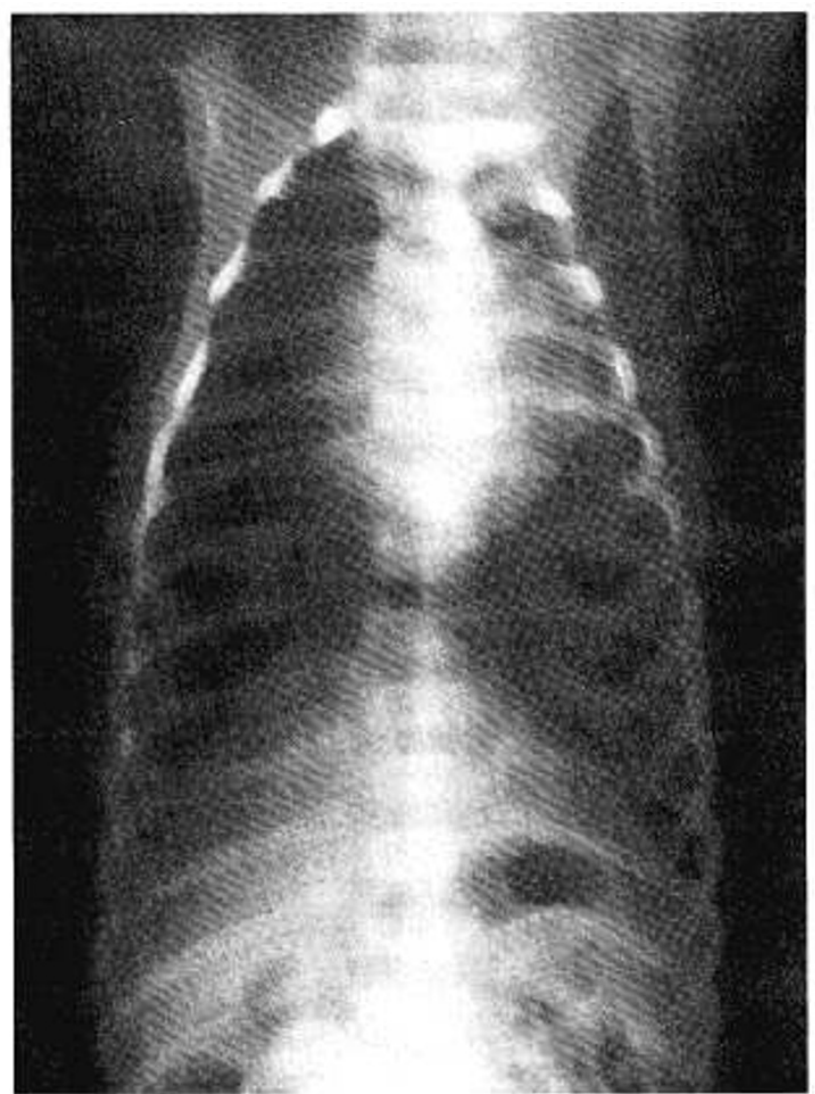

Fig. 2. Chest radiograph of a newborn piglet. The relative location of the heart and lungs explains the paucity of radioactivity in central thoracic region of the initial lung scintigrams (see Fig. 1).
Table 1. Calculated percentage lung retention of deposited submicronic aerosol in newborn piglets (mean $\pm S D$ )

\begin{tabular}{ccccc}
\hline & \multicolumn{2}{c}{ Healthy } & & Air emboli \\
\cline { 2 - 3 } & Spontaneous $(n=4)$ & IPPV $(n=5)$ & & IPPV $(n=6)$ \\
\hline Caudal half & $82 \pm 8.0$ & $97 \pm 7.4^{*}$ & & $71 \pm 18.3$ \\
Whole lung & $79 \pm 16.3$ & $79 \pm 9.2$ & & $73 \pm 9.1$ \\
\hline
\end{tabular}

${ }^{*} p<0.016$ compared to values obtained for the caudal half analysis of healthy spontaneous or air emboli IPPV.

caudal half of the lung was used in the determination of peripheral airway deposition (Table 1).

\section{DISCUSSION}

The objective of these experiments was to enhance our understanding of the sites of deposition for submicronic aerosols in newborn lungs. Our data demonstrate that approximately threefourths of the submicronic aerosol is deposited distal to ciliated airways. Cilia line the respiratory epithelium from the nasal passages to the respiratory bronchioles (7). Therefore these experimental data support theoretical calculations (3) and clinical observations (5) that submicronic aerosols are deposited predominantly in the terminal lung units. This supports the speculation that when ${ }^{99 \mathrm{~m}} \mathrm{Tc}-\mathrm{DTPA}$ is deposited in lungs using a submicronic aerosol its clearance rate predominantly reflects the epithelium in the distal lung unit.

The underlying assumption inherent to this method is that the mucociliary transport system will clear any deposited ${ }^{99 \mathrm{~m}} \mathrm{Tc}-\mathrm{S}$ within $24 \mathrm{~h}$. The rate of clearance of deposited matter depends on the location in the respiratory tract with mucociliary transport velocities being faster in central compared to peripheral airways. The transport velocity in terminal bronchioles, however, is still $0.7 \mathrm{~mm} / \mathrm{min}$ (7). Therefore our allowance of $24 \mathrm{~h}$ before obtaining our second lung scintigram is adequate. This is further supported by the observation that ${ }^{99 \mathrm{~m}} \mathrm{Tc}-\mathrm{S}$ could be visualized in the abdomen of the piglets $24 \mathrm{~h}$ after inhalation (Fig. 1).

The lung scintigrams that we obtained are only two-dimensional views. This produces an element of error in both methods of analysis that were used. The diaphragms are hemispherical structures and if the lowest regions of the lungs are included in the region of interest there will be some "contamination" from any ${ }^{99 m} \mathrm{Tc}-\mathrm{S}$ colloid present in the stomach and bowel at the time when the second scintigram is obtained. On the other hand when we include the rostral half of the lungs we count all regions of the lungs but by necessity include more of the trachea and main stem bronchi. Therefore when we only include the caudal half of the lung we likely overestimate the peripheral deposition due to the stomach contamination on the 24 -h scintigram, whereas when we use the entire lungs we underestimate the peripheral deposition because of the large airway deposition on the initial scintigram. It is likely that the true percentage of submicronic aerosol deposition on nonciliated airways is between the two values recorded, or approximately three-fourths of the deposited aerosol. This is slightly less than that seen in adult humans. Chamberlain et al. (6) used a similar technique and submicronic aerosol and found that approximately $85 \%$ of the particles were deposited on nonciliated airways.

There was a trend for the amount of peripheral deposition to be less in the animals that underwent intravenous air microembolization and IPPV appeared to enhance peripheral deposition when analyzed using only the caudal half of the lung (Table 1). These small differences would only have a small impact on the measurement of the clearance rate of inhaled and deposited ${ }^{99 m}$ Tc-DTPA. Many factors including lung volume, rate of inspiratory air flow, and peripheral airway function, influence the site of aerosol deposition within the lung $(3,8)$. We have no data 
to support or refute any of these specific mechanisms as being responsible for the increased lung retention in the caudal half of the lungs of piglets ventilated with IPPV.

An intravenous infusion of air microemboli was utilized to injure the lungs as this is a predominantly if not exclusively vascular lesion (4) and presumably did not affect the mucociliary transport system. It does result in a defect in gas exchange, however, in view of the well documented fall in $\mathrm{PaO}_{2}$ [see "Results" (4)]. It is unlikely that we induced alveolar edema: similar infusion rates do not increase lung water content in sheep (4), the $\mathrm{PaO}_{2}$ was $>200 \mathrm{~mm} \mathrm{Hg}$ on an $\mathrm{FIO}_{2}=1.0$ in the one pig studied, and none of the pigs had an elevated lung water content $24 \mathrm{~h}$ after embolization (see "Results").

In conclusion the present study demonstrates that a submicronic aerosol is predominantly deposited within the gas exchanging regions of both healthy and damaged neonatal piglet lungs. This supports the speculation that aerosols of this size are distributed in a similar fashion to gases $(5,6)$ and the clearance of incorporated solutes predominantly reflects the permeability of the terminal lung unit $(1,2)$. Caution must be exercised in extrapolating these results to the human infants as we have studied a different species, and the air microembolization is not analogous to all forms of lung injury.

\section{REFERENCES}

1. Jefferies AL, Coates G, Webber CE, O'Brodovich H 1984 Measurement of pulmonary clearance of radioaerosol using a portable sodium iodide probe. J Appl Physiol 57:1908-1913

2. Jefferies AL, Coates G, O'Brodovich H 1984 Pulmonary epithelial permeability in hyaline membrane disease. N Engl J Med 311:1075-1080

3. Task Group on Lung Dynamics 1966 Deposition and retention models for internal dosimetry of the human respiratory tract. Health Phys 12:173-207

4. Ohkuda K, Nakahara K, Binder A, Staub NC 1981 Venous air emboli in sheep: reversible increase in lung microvascular permeability. J Appl Physio 51:887-894

5. O'Brodovich HM, Coates G 1984 Quantitative ventilation-perfusion lung scans in infants and children: utility of a submicronic radiolabeled aerosol to assess ventilation. J Pediatr 105:377-383

6. Chamberlain MJ, Morgan WKC, Vinitski S 1983 Factors influencing the regional deposition of inhaled particles in man. Clin Sci 64:69-78

7. Satir P, Dirkson ER 1985 Function-structure correlations in cilia from mammalian respiratory tract system. In: Fishman AP, Fisher AB (eds) Handbook of Physiology: The Respiratory System, vol 1: Circulation and Non-respiratory Functions. American Physiological Society, Bethesda, MD pp 473-494

8. Brain JD, Valberg PA. State of the art. Deposition of aerosol in the respiratory tract. Am Rev Respir Dis 1979; 120:1325-1373 